\section{Juvenile nephronophthisis associated with skeletal abnormalities and hepatic fibrosis}

The association of juvenile nephronophthisis with skeletal abnormalities was first described by Mainzer et al. (1970), and that between congenital hepatic fibrosis and nephronophthisis by Boichis et al. (1973). We report a case in which the renal, hepatic, and skeletal features were combined.

\section{Case report}

The patient was the second of 3 boys born to unrelated parents at 39 weeks' gestation; birthweight $3.01 \mathrm{~kg}$. He failed to thrive from infancy. His first hospital admission was at the age of $5 \frac{1}{2}$ years with a 3-week history of anorexia, vomiting, abdominal pain, sweating, and 'heavy breathing'. Examination showed a small child (height $98 \mathrm{~cm}$, weight $13.3 \mathrm{~kg}$-both below 3rd centile) with pectus carinatum. He had signs of both dehydration and pulmonary oedema associated with cardiomegaly and hepatomegaly. Blood pressure after rehydration and treatment of heart failure was $220 / 120$ mmHg. The retinae were normal.

The results of investigations showed $\mathrm{Hb} 6.6 \mathrm{~g} / \mathrm{dl}$; white cell count $5 \cdot 2 \times 10^{9} / 1\left(5200 / \mathrm{mm}^{3}\right)$; serum urea $128 \mathrm{mg} / 100 \mathrm{ml}(21 \cdot 2 \mathrm{mmol} / 1)$, sodium $140 \mathrm{mmol} / 1$, (140 $\mathrm{mEq} / \mathrm{l})$, potassium $4 \cdot 7 \mathrm{mmol} / 1 \quad(4 \cdot 7 \mathrm{mEq} / \mathrm{l})$, chloride $115 \mathrm{mmol} / 1$ (115 mEq/l), creatinine $3 \mathrm{mg} / 100$ $\mathrm{ml}(265 \mu \mathrm{mol} / 1)$, calcium $8.3 \mathrm{mg} / 100 \mathrm{ml}(2.08 \mathrm{mmol} / \mathrm{l})$, phosphorus $7.7 \mathrm{mg} / 100 \mathrm{ml}(2.5 \mathrm{mmol} / \mathrm{l})$, alkaline phosphatase $15 \mathrm{KA}$ units, total protein $55 \mathrm{~g} / 1$, albumin $30 \mathrm{~g} / \mathrm{l}$, total bilirubin $0.4 \mathrm{mg} / 100 \mathrm{ml}(6.8 \mu \mathrm{mol} / \mathrm{l})$, SGOT 17 IU/1, normal levels for the $\mathrm{C} 3$ and $\mathrm{C} 4$ components of complement, glomerular filtration rate (as determined by ${ }^{51}$ chromium EDTA slope clearance) $11.2 \mathrm{ml} / \mathrm{min}$ per $1.73 \mathrm{~m}^{2}$. His urine contained a few granular casts but no cells, and urinary protein excretion was $92 \mathrm{mg} / \mathrm{h}$ per $\mathrm{m}^{2}$ (normal, $<4 \mathrm{mg} / \mathrm{h}$ per $\mathrm{m}^{2}$ ).

Intravenous pyelography showed normal sized kidneys with poor function, and also revealed metaphyseal chondrodysplasia of the femoral necks (Fig. 1). This prompted a skeletal survey which showed cone shaped epiphyses in the phalanges of both the hands and the feet (Fig. 2). (The radiological features are described in detail elsewhere (Chakera, 1975). Renal biopsy showed appearances consistent with juvenile nephronophthisis (see below).

The hypertension proved difficult to control and intermittent peritoneal dialysis became necessary for increasing azotaemia and hyperkalaemia. The child's

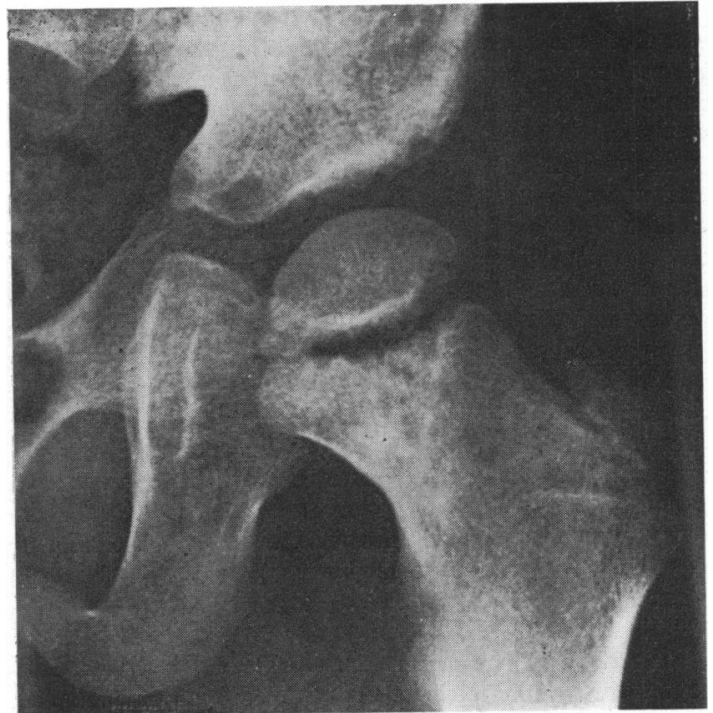

FIG. 1.-Metaphyseal chondrodysplasia of femoral neck. (By permission of Editor of British Journal of Radiology.)

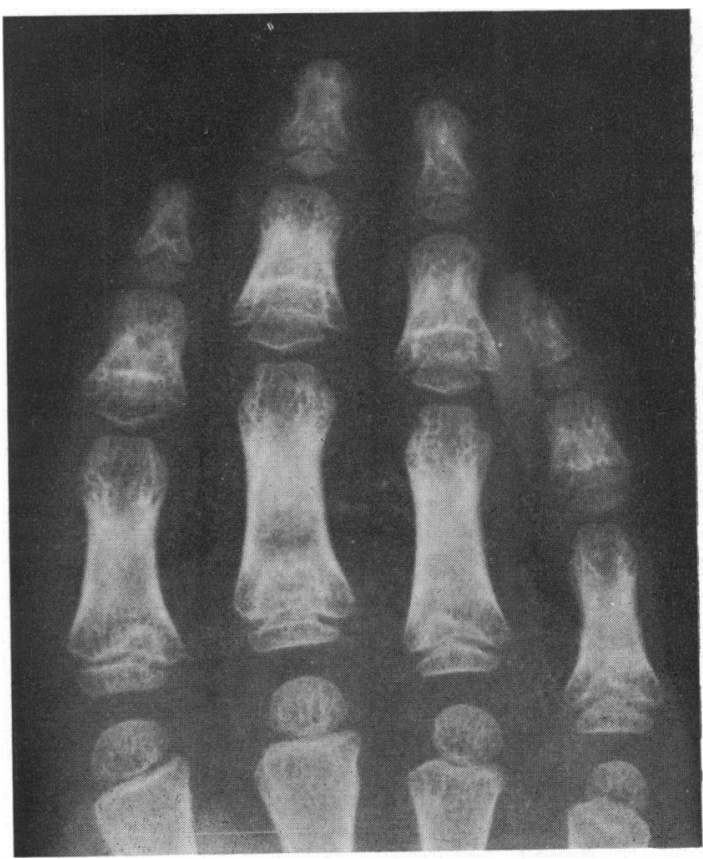

FIG. 2.-Phalangeal epiphyses are cone shaped. 
general condition slowly deteriorated and he died aged 6 years while awaiting renal transplantation.

There was no known family history of renal or hepatic disease and $x$-rays of the parents and brothers showed no evidence of a peripheral dysostosis.

Post-mortem findings. The length of the body was $100 \mathrm{~cm}$ (below $3 \mathrm{rd}$ centile) and there was slight generalized oedema. The internal abnormalities were confined to the renal, cardiovascular, and skeletal systems. There was left ventricular hypertrophy (heart weight $144 \mathrm{~g}$, expected $94 \mathrm{~g}$ ). The kidneys were uniformly small (left $31 \mathrm{~g}$, right $29.5 \mathrm{~g}$-expected weight $70 \mathrm{~g}$ each), the surfaces were finely granular but the capsules stripped easily. The cortex was reduced to $0.3 \mathrm{~cm}$ and there was no focal scarring. The renal pelves and the lower urinary tract were normal. The liver was enlarged, pale brown-yellow, and showed slight nodularity ( $1150 \mathrm{~g}$-expected $640 \mathrm{~g}$ ). Section of the vertebral bodies performed at the time of necropsy showed no abnormality. The right femur was of normal configuration: section after fixation showed a normal distal epiphyseal region, but proximally there were several small cartilaginous foci in the medical part of the metaphysis. The bone trabeculae appeared normal.

Microscopy. The histological features of the kidneys were similar to those of the needle biopsy (Fig. 3).

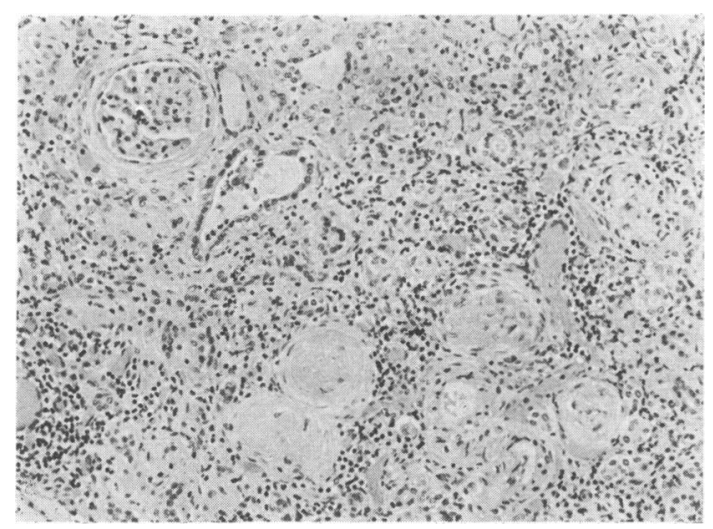

FIG. 3.-Kidney. At top left is a relatively normal glomerulus with periglomerular fibrosis and dilatation of adjacent tubules. Elsewhere there is sclerosis of glomeruli, atrophy of tubules, and round cell infiltration. (H. \& E. ×100.)

There was diffuse interstitial fibrosis and focal infiltration by lymphocytes with scattered histiocytes. The majority of the glomeruli were sclerosed with intracapsular and pericapsular fibrosis; others showed periglomerular fibrosis with relatively normal tufts. The tubules in some areas were dilated and in others atrophic with thickened basement membranes. These two changes often formed a pattern of alternating dilatation and atrophy. There was no abnormality in the blood vessels.

In the liver the portal tracts showed fibrosis with proliferation of small bile ducts and a scanty infiltrate of lymphocytes, histiocytes, and polymorphonuclear neutrophil leucocytes (Fig. 4). The liver parenchyma

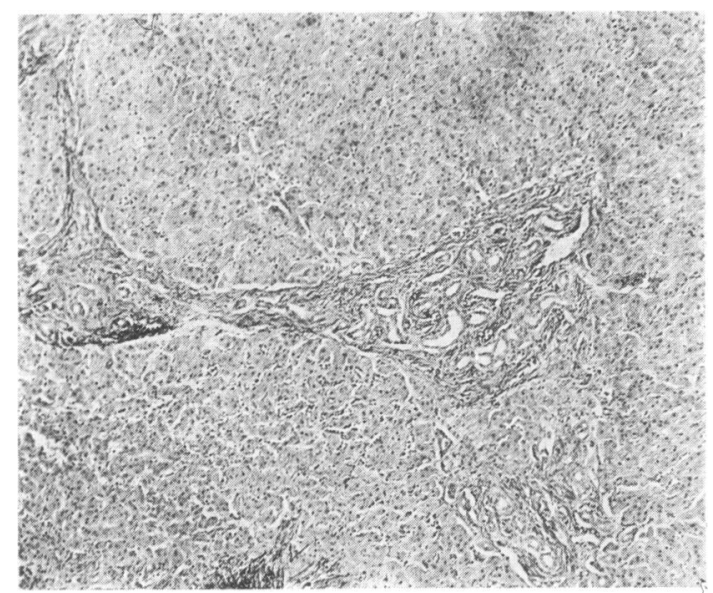

FIG. 4.-Liver showing broad fibrous portal tracts joined together and containing numerous small bile ducts and scanty inflammatory cells. $(H . \& E . \times 45$. $)$

and central veins were unremarkable except that some liver cells were incorporated into the fibrous tissue of the portal tracts. There was no bile stasis.

Sections of bone showed slight widening of osteoid seams (osteomalacia), but no evidence of osteitis-fibrosa.

\section{Discussion}

The association of pathological changes in the liver and kidney is well recognized. In adults there is the dominant form of polycystic disease, and in children there is a recessive form which shows portal fibrosis with ectasia of the bile ducts and renal distal tubules (Blyth and Ockenden, 1971). Less common conditions showing cystic changes in the kidney and fibrosis in the liver are reviewed by Bernstein and Kissane (1973). They have other associated features such as pancreatic fibrosis and cerebral abnormalities which distinguish them from the present case.

Both the clinical features and the histopathological changes in the kidney in our patient are consistent with the condition of juvenile nephrophthisis as first described by Fanconi et al. (1951). This is an important cause of chronic renal failure in children and accounts for more than $20 \%$ of deaths from this cause in this hospital (Betts and Forrest-Hay, 1973). Fanconi's original report established that there was a familial tendency. Since then an 
association with defective vision and retinal dystrophy has been frequently recognized (Senior, 1973; Betts and Forrest-Hay, 1973). There was no evidence of retinal changes in the present case, but there were two additional features which have only recently been found in association with juvenile nephronophthisis.

A family described by Boichis et al. (1973) showed hepatic portal fibrosis in addition to nephronophthisis. The liver changes, confirmed at necropsy in 2 children, were similar to those in our patient, and were regarded as a form of congenital hepatic fibrosis by the authors. We have reservations about this terminology as there is no evidence that either the hepatic or renal changes are present at birth.

Renal osteodystrophy is a common complication of juvenile nephronophthisis (Betts and ForrestHay, 1973) but dysostosis appears to be rare. The cone-shaped phanalgeal epiphyses and metaphyseal chondrodysplasia of the femoral necks in our case are quite distinct from renal osteodystrophy and appear identical with those described in association with nephronophthisis by Mainzer et al. (1970, Case 2).

It seems, therefore, that there are at least three conditions which may occur in conjunction with juvenile nephronophthisis-retinal dystrophy, dysostosis, and portal fibrosis. The retinal changes appear to be the commonest. The 2 children described by Mainzer et al. (1970) showed all but the portal fibrosis, while in our case only the retinal dystrophy was lacking.

\section{Summary}

A case of juvenile nephronophthisis with hepatic portal fibrosis and dysostosis of the phalanges and femoral necks is described.

We thank Dr. F. C. Leyland for referring the patient, and Drs. R. H. R. White, A. H. Cameron, and R. Astley for guidance.

\section{REFERENCES}

Bernstein, J., and Kissane, J. M. (1973). Hereditary disorders of the kidney. Perspectives in Pediatric Pathology, Vol. 1, p. 117. Ed. by H. S. Rosenberg, and R. P. Boland. Yearbook Medical Publishers, Chicago.

Betts, P. R., and Forrest-Hay, I. (1973). Juvenile nephronophthisis. Lancet, 2, 475.

Blyth, H., and Ockenden, B. G. (1971). Polycystic disease of kidneys and liver presenting in childhood. Fournal of Medical Genetics, 8, 257.

Boichis, H., Passwell, J., David, R., and Miller, H. (1973). Congenital hepatic fibrosis and nephronophthisis. Quarterly fournal of Medicine, 42, 221.

Chakera, T. M. H. (1975). Peripheral dysostosis associated with juvenile nephronophthisis. British fournal of Radiology, 48, 765.
Fanconi, G., Hanhart, E., Albertini, A. V., Ưhlinger, E., Dolivo, G., and Prader, A. (1951). Die familiäre juvenile Nephronophthise (die idiopathische parenchymatöse Schrumpfniere). Helvetica Paediatrica Acta, 6, 1.

Mainzer, F., Saldino, R. M., Ozonoff, M. B., and Minagi, H. (1970). Familial nephropathy associated with retinitis pigmentosa, cerebellar ataxia and skeletal abnormalities. American fournal of Medicine, 49, 556.

Senior, B. (1973). Familial renal-retinal dystrophy. American fournal of Diseases of Children, 125, 442.

D. G. Robins, ${ }^{\star}$ T. A. French, and T. M. H. Chakera Departments of Nephrology, Pathology, and Diagnostic Radiology, Children's Hospital, Ladywood Middleway, Birmingham B16 8ET.

*Correspondence to Dr. D. G. Robins, Frimley Park Hospital, Frimley, Surrey, GU16 5UJ.

\section{Juvenile nephronophthisis associated with retinal pigmentary dystrophy, cerebellar ataxia, and skeletal abnormalities}

Juvenile nephronophthisis associated with retinitis pigmentosa was first described by Senior, Friedmann, and Braudo in 1961, and a number of cases have been reported since (Meier and Hess, 1965; Betts and Forrest-Hay, 1973; Senior, 1973). Besides the renal and ocular abnormalities, mental retardation, chromosomal defects, and skeletal abnormalities have been observed in some patients (Fontaine et al., 1970; Sarles et al., 1968; Antoine et al., 1963), but the association of interstitial nephritis, retinitis pigmentosa, cerebellar ataxia, and endochondral dysostosis was first recorded by Mainzer et al. (1970). This paper describes another patient with the latter findings.

\section{Case report}

A male, born on 6 July 1961, was admitted in March 1971 with a 2-year history of renal disease.

Family history. After a complete examination (laboratory, ophthalmological, electroretinographic, audiometric, and $x$-ray findings) his mother, father, and only sister were found to be in good health except for abnormalities of pelvic endochondral ossification revealed by the father's $x$-ray examination.

He was the second child. Pregnancy and delivery were normal. By the end of the first year of life, failure to thrive was noted, together with some skeletal abnormalities. In the fifth year of life, poor adaptation to dark, unstable gait (he frequently fell), and polydipsia were noted. In 1969, when he was 8 , he was hospitalized for the first time because of convulsions. He was then noted to be of short stature, slightly azotaemic, with serum creatinine $1 \mathrm{mg} / 100 \mathrm{ml}(88 \cdot 4 \mu \mathrm{mol} / \mathrm{l})$. Blood presure was normal. 